\title{
Analysis of the Status and Development Path of Guangzhou's Cultural and Creative Industry (CCI)
}

\author{
Jinfeng Wang ${ }^{1, *}$ and Shiya Huang ${ }^{2}$
}

\begin{abstract}
${ }^{1}$ Creative and Design dept. of City College of Dongguan Institute of Technology, Dongguan, China
${ }^{2}$ Finance and Trade dept. of City College of Dongguan Institute of Technology, Dongguan China

*Corresponding author. Email:1053363168@qq.com
\end{abstract}

\begin{abstract}
Cultural and creative industries can play a great role in boosting employment, promoting capital operation and developing a diversified economy. This paper focuses on the relevant concepts and connotations of the cultural and creative industry, and explores the development path of the cultural and creative industry in Guangzhou by combining the development status quo and existing problems in the current development process.

Keywords: Guangzhou; Cultural and Creative Industry; Status quo; Industrial chain
\end{abstract}

\section{INTRODUCTION}

The United Nations released a report titled "Cultural Age: Overview on the Global Cultural and Creative Industry" in 2016. It was shown that the cultural and creative industry played a great role in the promotion on employment and capital operation as well as the development of the diversified economy. According to the data of the National Bureau of Statistics, the revenue of Chinese cultural and related industrial enterprises above designated size reached 8662.4 billion yuan with a year-on-year growth rate of $7.0 \%$ in 2019 . Thereinto, the output value of the cultural and creative industry has grown rapidly year by year, which makes important contribution to Chinese economic development. The Guangzhou Municipal Government has attached great importance to the development of the cultural and creative industry in recent years. The high-end strategic positioning of Guangzhou's cultural industry was clarified in "Guangzhou's Implementation Opinions on the Acceleration of the Innovation and Development of the Cultural Industry" issued in November, 2018. According to the survey of "Guangzhou's Blue Book: Report on the Development of Guangzhou's Cultural and Creative Industry (2019)", the added value of Guangzhou's cultural and creative industry reached 280 billion yuan, accounting for $13 \%$ of the urban GDP in 2017. It has become the pillar industry of Guangzhou City. However, with the short development history, it started late. It is the decisive year for the establishment of a comprehensive well-off society as well as the end of "The 13th Five-Year Plan" in Guangdong Province. As a result, as the economic center of
Guangdong Province, Guangzhou City is faced with the great internal pressure and challenge of serious resource and environment constraints and economic structure adjustment and the great external competition pressure from Beijing's and Shanghai's rapid development. It is necessary to develop the cultural and creative industry vigorously and choose the right development path in this critical period. It plays a great strategic role in the promotion of economic structure adjustment, industrial upgrading, new competitive advantage cultivation and cultural soft power enhancement in Guangzhou City.

\section{DEFINITION OF THE CONCEPT AND INDUSTRIAL SCOPE OF THE CULTURAL AND CREATIVE INDUSTRY}

The research on the cultural and creative industry as a new industry is still at the early stage. There are different descriptions of the concept, connotation and scope of the cultural and creative industry in different countries and regions. In terms of the naming and connotation definition of the Chinese cultural and creative industry, it has not reached a unified national standard so far. There are two sets of statistical formulas for the statistical data of provinces and key development cities, which separates the cultural industry and the cultural and creative industry for statistical analysis. Different statistical standards can easily lead to data contradictions between localities and provinces and between provinces and countries. There are different statistical standards for the comparison among Beijing City, Shanghai City and Guangzhou City. 
Table 1 Definition and classification of the cultural and creative industry in Guangzhou City, Beijing City and Shanghai City

\begin{tabular}{|c|c|c|c|}
\hline District & Connotation & Classification & Source \\
\hline Guangzhou & $\begin{array}{l}\text { Not only is the industrial agglomeration with the } \\
\text { deep combination among "culture, creativity and } \\
\text { technology" related to culture, but it is also } \\
\text { different from culture. }\end{array}$ & $\begin{array}{l}\text { Five categories: cultural media, } \\
\text { technological development, } \\
\text { design, consulting \& planning and } \\
\text { fashion consumption }\end{array}$ & $\begin{array}{l}\text { "Report on the } \\
\text { Development of } \\
\text { Guangzhou's Cultural } \\
\text { and Creative Industry } \\
\text { in 2014" }\end{array}$ \\
\hline Beijing & $\begin{array}{l}\text { It refers to the industrial agglomeration with } \\
\text { inherent relations to provide the cultural } \\
\text { experience for the public by taking creation and } \\
\text { innovation as the fundamental means, cultural } \\
\text { content and creative achievements as the core } \\
\text { value and the realization or consumption of } \\
\text { intellectual property as transaction characteristics. }\end{array}$ & $\begin{array}{l}\text { Category 9: culture and art; press } \\
\text { and publication; radio, television } \\
\text { and film; software, network and } \\
\text { computer service; advertising and } \\
\text { exhibition service; art trading; } \\
\text { design service; tourism, leisure } \\
\text { and entertainment service; other } \\
\text { auxiliary services }\end{array}$ & $\begin{array}{l}\text { "Classification } \\
\text { Standard for Beijing's } \\
\text { Cultural and Creative } \\
\text { Industry" (2006) }\end{array}$ \\
\hline Shanghai & $\begin{array}{l}\text { With the core of human creativity, the element of } \\
\text { culture, the driving force of creativity, the support } \\
\text { of technology, the guidance of market, the carrier } \\
\text { of products and the starting point of brands, it } \\
\text { forms an integrated industrial chain and new } \\
\text { format to integrate the cultural industry and the } \\
\text { creative industry by combining comprehensive } \\
\text { culture, creativity, technology, capital, } \\
\text { manufacturing and other elements. }\end{array}$ & $\begin{array}{l}\text { Category 11: media; art; industrial } \\
\text { design; architectural design; } \\
\text { fashion and creativity; network } \\
\text { information; software and } \\
\text { computer service; consulting } \\
\text { service; advertising and exhibition } \\
\text { service; leisure and entertainment } \\
\text { service; cultural and creative } \\
\text { industry. }\end{array}$ & $\begin{array}{l}\text { "Catalogue of } \\
\text { Shanghai's Cultural and } \\
\text { Creative Industry" } \\
\text { (2013) }\end{array}$ \\
\hline
\end{tabular}

The research standards and data of the cultural and creative industry proposed in the paper are based on the classification of "Report about the Development of Guangzhou's Cultural and Creative Industry in 2014"[1].

\section{STATUS OF GUANGZHOU'S CULTURAL AND CREATIVE INDUSTRY}

\subsection{The steady development and gradually growing scale of Guangzhou's Cultural and Creative Industry is maintained on the whole}

As an important place to inherit Lingnan culture, Guangzhou City is endowed with a strong cultural heritage due to its historical culture. In terms of the current development level, it is obvious that the comprehensive strength and competitiveness of Guangzhou's cultural and creative industry are in the forefront of the country. The added value of Guangzhou's cultural and creative industry grew from 215.706 billion yuan in 2014 to 320 billion yuan in 2019 , resulting in a growth rate of $67.4 \%$. Its proportion in Guangzhou's GDP grew from $12.9 \%$ to $13.9 \%$ [2]. It was indicated that the development scale of Guangzhou's cultural and creative industry had been expanded rapidly in recent years. It also meant that in terms of the economic status, Guangzhou's cultural and creative industry got increasingly important, becoming an important pillar industry of the local national economy. In 2017, there were more than three hundred and forty-eight cultural and creative industrial parks (bases), including seventeen national parks (bases), seventeen provincial parks (bases) and thirty-three municipal parks (bases). The output value of Guangzhou's creative industrial parks exceeded 12 billion yuan in 2017 as well as 15 billion yuan in 2018 , growing by $63.8 \%$ compared with two hundred and twentytwo industrial parks in 2016. It was clearly showed that Guangzhou's cultural industrial parks were developing very rapidly and the development quality was taken into account at the same time.

\subsection{Guangzhou's per capita consumption of the cultural and entertainment service ranks first in China}

In Guangzhou City, the consumption of the cultural and entertainment service is expanded year by year and the per capita cultural consumption level is at the forefront of the country. In 2017, the per capita cultural consumption amounts of urban residents of Beijing City, Shanghai City and Shenzhen City were 4325 yuan, 5087 yuan and 3559 yuan, accounting for $10.7 \%, 12 \%$ and $9.3 \%$ of the per capita consumption expenditure respectively. The per capita cultural consumption amount of urban residents of Guangzhou City in the same period was 5405 yuan, accounting for $13.3 \%$ of the per capita consumption expenditure. The city was ranked first among the first-tier cities in China [3]. 


\subsection{The new format represented by the digital music industry is developing rapidly}

With the rapid development of the Internet information technology, the further progress of the strategies of "culture plus" and "Internet plus" and the accelerated integration between the cultural and creative industry and other industry in Guangzhou City, the new formats of the cultural and creative industry have appeared constantly. In addition, it has promoted the development of the digital content industry vigorously. Thereinto, the digital music industry is the most remarkable. With the rapid development of the local digital musical industry, Guangzhou City has become an important city of the national digital musical industry[4]. In terms of digital musical enterprises, several well-known domestic digital musical enterprises have appeared constantly in Guangzhou City, such as Kugou, Litchi, iMusic and Wo Music. The revenue of Kugou as a representative enterprise exceeded 10 billion yuan in 2018 . In addition to digital music, online live broadcasting is a highlight in Guangzhou City. Some leading enterprises of network live broadcasting have gathered here, such as YY, Huya, Kugou and Netease CC. With revenue of 1.57 billion yuan, YY became a leading enterprise in the national network lives broadcasting industry in 2018. In addition, Huya won the investment of 460 million dollars from Tencent in Mar. 2018. On May 11th, 2018, it was officially listed on New York Stock Exchange, becoming the first listed company in China.

\subsection{The aggregation effect of Guangzhou's cultural and creative industry becomes obvious increasingly}

The aggregation of the cultural and creative industry refers to the phenomenon of strong space concentration involved in the creation and production of the cultural and creative industry. It is generally manifested as the cultural and creative industry area, the animation industry park and the original design area. The aggregation of the cultural and creative industry is conducive to the professional division of labor and cooperation among different types of enterprises on the industrial chain, which can maximize the use of cultural resource, resulting in the aggregation effect. As a famous industrial park with 1978 Cultural Creative Town, Guangzhou T.I.T Creative Industrial Park, Zhujiang Party Pier Beer Culture\&Art Zone, Former Butterfield \& Swire Godowns \& Wharves and Redtory Art \& Design Factory, Yangcheng Creative Industry Zone is taken as an example. There are more than three hundred and forty-eight cultural and creative industrial parks (bases) in Guangzhou City at present, including seventeen national parks (bases), seventeen provincial parks (bases) and thirty-three municipal parks (bases). The total output value of these parks exceeded 12 billion yuan in 2017 and 15 billion yuan in 2018[5].

\section{PROBLEMS ABOUT THE DEVELOPMENT OF GUANGZHOU'S CULTURAL AND CREATIVE INDUSTRY}

\subsection{The intellectual property protection of the cultural and creative industry is not perfect}

Intellectual property is essential for the survival of the cultural and creative industry. Intellectual property protection is the premise and foundation for the development of the cultural and creative industry. Without the protection of laws and policies, the development prospect of the cultural and creative industry will be poor even if there are more investment policies to encourage the development of the cultural and creative industry[6] Because of the high early-stage creative development and design investment and low later-stage copy cost of the cultural and creative industry, some immoral businesses can directly steal others' achievements and sell them at a lower price after seeing the business opportunity. In the long run, it can cause great economic losses to the original enterprises so as to hinder industrial development greatly. Due to the imperfection of relevant laws and regulations and the incomplete implementation of policies as well as the high cost and long-time of intellectual property protection, most piracy activities fail to be punished so that piracy becomes increasingly rampant. It harms the production of original works, restricts the development of the cultural and creative industry to a great extent and weakens the creative enthusiasm of creators at the same time.

\subsection{The speed of cultural and creative talent training fails to meet the need for development}

The cultural and creative industry is an industry with the production factors of wisdom and creativity, which also determines that every link of the creative industry is inseparable from talents. So the development of the industry can't do without the development and cultivation of talents. A lot of excellent talents are cultivated and a large number of high-quality talents are absorbed by means of rich educational resource, superior geographical position and economic advantages in Guangzhou City. However, there are still some problems, such as insufficient talents, insufficient high-level compound talents and serious brain drain[7].

\subsection{The industrial chain is imperfect and the industrial integration is poor}

Generally speaking, the industrial chain refers that a closed-loop to gather enterprises from different industries and realize resource sharing is formed in the whole park. As mentioned previously, Yangcheng Creative Industry Zone is taken as an example. The complete industrial chain 
determines the long-time survival of the whole park. There are some problems about the development of Guangzhou's cultural and creative industry, such as the imperfect industrial chain of most industrial parks, the poor or even mismatched inner integration of the closed-loop and the lack of a public service platform for communication resulting in the lack of cooperation and communication among enterprises and the failure to make full use of information resource.

\subsection{The international market competition is intensified and the product competitiveness is insufficient}

This year, due to the rapid development of the market economy and the broad development prospect in China, the unlimited business opportunities of the Chinese market have been shown to the world, resulting in a lot of foreign investment. Since the cultural and creative industry was popular abroad but just emerging in China, with the resource, several cultural and creative enterprises and associations from developed countries like the United States, Japan, Britain, France and South Korea have been settled in Chinese economically developed cities including Guangzhou City. The effect of the entry of foreign capital is divided into two parts. On the one hand, foreign investors see the development space of the Chinese cultural and creative industry and occupy some resources before the Chinese people have noticed it. On the other hand, it is conducive to learning the advanced ideas of foreign cultural and creative enterprises, accelerating the starting speed of Guangzhou's cultural and creative industry and developing the international market quickly in Guangzhou City. However, in this case, it brings great development pressure to Guangzhou's local cultural and creative enterprises. In the era of economic globalization, with the increasingly close exchanges among countries or regions, Guangzhou's cultural and creative industry tends to be more international. It is difficult to promote and popularize Guangzhou's cultural and creative products in the international market. The fundamental reason is that Guangzhou's cultural and creative products are endowed with less obvious competitive advantages as well as insufficient technology and creativity, failing to meet the need of the international market.

\section{ANALYSIS OF THE DEVELOPMENT PATH OF GUANGZHOU'S CULTURAL AND CREATIVE INDUSTRY}

\subsection{Strengthen intellectual property protection and improve the industrial development environment}

Intellectual property is the core of the cultural and creative industry. Only by protecting the intellectual achievements of industrial personnel fully, can we ensure the development of the cultural and creative industry in a good and positive environment. A perfect intellectual property protection mechanism can stimulate the creative potential of talents, resulting in more creative desire and passion. It is necessary to establish a set of sound and perfect intellectual property protection laws and policies applicable to the development of the cultural and creative industry, strengthen the supervision on industrial law enforcement, and severely punish the behavior in violation of intellectual property in Guangzhou City. In addition to creating a good legal and policy environment for the intellectual property protection of the cultural and creative industry, cultural and creative enterprises are required to improve their intellectual property protection awareness. It is necessary for different levels and types of governments and schools to further promote intellectual property protection and popularize the legal knowledge of intellectual property through various channels. Enhance the social awareness on intellectual property protection, make the public realize the illegality of intellectual property infringement and improve the intellectual property protection awareness of the whole society.

\subsection{Improve the talent training policy and the high-end talent introduction policy}

Paying attention to the cultivation and introduction of talents is an important measure to promote the vigorous development of the cultural and creative industry as a knowledge-intensive industry. Improve the policy for the introduction of cultural and creative industrial talents, especially high-level compound talents. Set up incentive measures for talent introduction. Integrate the talent training of the cultural and creative industry into the development plan of Guangzhou's higher education. Cultivate professional talents and encourage universityenterprise cooperation to improve the vitality of the cultural and creative industry by bringing fresh vitality continuously. Pay attention to the current talent demand and the future talent reserve demand, gather and encourage talents constantly and lay a smart foundation for the development of the cultural and creative industry.

\subsection{Reasonable planning of industrial parks to form a perfect industrial chain}

Generally speaking, the industrial chain refers that a closed-loop to gather enterprises from different industries and realize resource sharing is formed in the whole park. As mentioned previously, Yangcheng Creative Industry Zone is taken as an example. The complete industrial chain determines the long-time survival of the whole park. There are some problems about the development of Guangzhou's cultural and creative industry, such as the imperfect industrial chain of most industrial parks, the poor or even mismatched inner integration of the closed-loop and the 
lack of a public service platform for communication resulting in the lack of cooperation and communication among enterprises and the failure to make full use of information resource.

\subsection{Speed up the process of industrial internationalization and enhance international competitiveness}

The value of cultural and creative industrial products belonging to the experiential economy can be only realized in the process of consumer experience[8]. Chinese national history and culture are incomparable in the world. As a place to inherit Lingnan culture, Guangzhou City is endowed with a colorful historical culture. With the highlight of Lingnan culture as well as the product creativity of the current popular technology in the international market, it is possible to show Guangzhou's traditional culture to the world according to the requirements of the new era to enhance the international competitiveness of products in Guangzhou's cultural and creative industry.

"Creative City" has become a slogan for the global development of cities. As an emerging industry of the times, the cultural and creative industry has become an important force in the economic development of various countries. It becomes a pillar industry gradually in various countries. It is necessary to build an international metropolis by promoting the development of the cultural industry vigorously and enhancing the cultural soft power[9]. As Guangdong's provincial capital, Guangzhou City is endowed with unique development advantages. It is possible to create the cultural and creative industry with Lingnan cultural characteristics, improve the core competitiveness and create an urban "business card" belonging to Guangzhou City by taking advantage of the opportunity of the new era in Guangzhou City as the center of Lingnan culture.

\section{CONCLUSION}

From what has been discussed above, to speed up Guangzhou's cultural and creative industry, strengthen the intellectual property protection and improve the industrial development environment, improve the talent training policy and the high-end talent introduction policy, reasonable planning of industrial parks to form a perfect industrial chain, speed up the process of industrial internationalization and enhance international competitiveness are needed.

\section{ACKNOWLEDGMENT}

This paper is the phased research results of the digital media art of quality engineering project (2019) of the Department of Education of Guangdong Province.

\section{REFERENCES}

[1]Gan Xin. "Report on the development of Guangzhou's cultural and creative industry in 2014" [M]. Beijing: Social Sciences Academic Press (CHINA). 2014.2-25

[2]Xu Yonghong. "Guangzhou blue book: report on the development of Guangzhou's cultural and creative industry (2019)". [M]. Guangzhou Academy of Social Sciences. 2019- 8-27

[3] Xu Yonghong. "Guangzhou blue book: report on the development of Guangzhou's cultural and creative industry (2018)" [M]. Guangzhou Academy of Social Sciences. 2018-11-20.

[4]Fan Yupeng. "Research on the status of Guangdong's cultural and creative industry" [J]. Science \& Technology Vision, 2014 (29): 23-25

[5]Zeng Ya. "Encouragement on the transformation of old factory buildings for the creative industry" [N]. Nanfang Daily. 2010-08-04

[6]Sun Yurong. "Path selection of the intellectual property protection of the cultural and creative industry in the era of big data" [J]. Journal of Beijing Union University (Humanities and Social Sciences) 2014,12 (02): 54-59

[7]Zeng Huifen, Chen Li and Huang Zhihua. "Investigation and analysis of the status and development demand of intellectual property talents in Guangzhou City" [J]. Strategy for Development and Innovation of Science and Technology. 2018,2 (02): 1521

[8]Xiong Chengyu. "Enlightenment of the agglomeration development of the English creative industry" [J]. Qiushi, 2012 (07): 58-60

[9]Li Yi, Zhang Ting, Jia Qihao and Geng Ya'nan. "Research on the integration mode of the hotel industry and the cultural and creative industry based on the cultural industry integration theory - Taking BTG Hotels as an example" [J]. Special Zone Economy. 2020 (08): 128-13. 